\title{
Problemas de ensino e de aprendizagem em perímetro e área de figuras planas
}

\author{
Problems of both teaching and learning in the perimeter and area \\ of flat figures
}

\author{
Jamile Aparecida Saulino do Santos \\ milesaulino@yahoo.com.br
}

\begin{abstract}
Resumo
Este trabalho pretende evidenciar os problemas de ensino e de aprendizagem relacionados às Grandezas Geométricas perímetro e área de figuras planas. $\mathrm{O}$ foco de análise incide em verificar o entendimento dos alunos em relação a problemas de perímetro e área; identificar as possíveis dificuldades vivenciadas por professores de Matemática no ensino desses conceitos e compreender como estes analisam as produções e os erros dos alunos. Os dados foram coletados a partir das respostas dos alunos de duas questões retiradas do Sistema de Avaliação de Rendimento Escolar do Estado de São Paulo (SARESP) de 2007 e 2008, referentes ao cálculo de perímetro e área, entrevista com treze desses alunos e de entrevista com três professores de Matemática que lecionam no Ensino Fundamental. Os relatos dos alunos indicam um sério problema de ensino, visto que não há apreensão dos conceitos. Os professores revelam uma formação docente deficitária e práticas tradicionais de ensino restritas à memorização de definições, repetição de exercícios e atividades pouco significativas.
\end{abstract}

Palavras Chave: Grandezas Geométricas, Ensino de Matemática, Formação de Professores.

\begin{abstract}
This essay plans to put into evidence the problems of teaching and learning connected to the Geometrical perimeters and of flat figures. The focus of our analyses is to verify the students understanding in connection to the problems of perimeter and area; identify the possible difficulties that Mathematics the teachers face in teaching these concepts, and understanding how they analyze the student's production and mistakes. The information was collected from the answers given by students to two issues presented to them in the System if Evaluation of School Performance in the State of São Paulo (SARESP), during the years 2007 and 2008, referring to the calculus of the perimeter and area, interviews with 13 students and interviews with 3 Mathematics teachers that teach at the Elementary Level. The narratives produced by the students refer a serious teaching problem, given the fact that there is no apprehension of the concepts being taught. The teachers disclose a deficient docent training and traditional teaching practices of memorizing definitions and the repetition of activities and exercises that are not meaningful.
\end{abstract}

Keywords: Geometrical Sizes. The Teaching of Mathematics. Teacher's Training. 


\section{Introdução}

Este texto foi elaborado com base na análise dos resultados de uma dissertação de Mestrado, a qual investigou problemas de ensino e de aprendizagem relacionados às Grandezas Geométricas perímetro e área de figuras planas. Atuando há dez anos no ensino público paulista percebi que os alunos apresentam grandes dificuldades em relação à Geometria, uma área da Matemática muito presente no nosso cotidiano. Autores como Crescenti $(2008,2005)$, Pavanello (1989), Lorenzato (1995), salientam sua importância por ser uma área rica em aplicações práticas, que auxilia na resolução de problemas e contribui na aquisição, por parte dos alunos, de habilidades como: observar, comparar, descrever, abstrair, generalizar.

Apesar da relevância da Geometria, percebe-se que o seu ensino, no Brasil, foi relegado a um plano secundário. Diversas são as causas responsáveis por esse abandono, apontadas por autores como Lorenzatto (1995), Gazire (2000), Nacarato (2001), Pavanello (1989, 1993), Nacarato e Passos (2003): a influência do Movimento da Matemática Moderna (MMM) nas décadas de 1960 e 1970 acarretou numa formação de base muito precária em Geometria; a formação inicial deficitária nessa área da Matemática e, consequentemente, a deficiência de conhecimento geométrico por parte do professor, o que pode culminar em despreparo e insegurança de ensiná-lo.

Têm se dedicado ao estudo das dificuldades dos alunos e professores no entendimento de conteúdos geométricos, especificamente nos conceitos de perímetro e área, pesquisadores brasileiros, como Chiummo (1998), Facco (2003), Andrade (2007) e Baldini (2004), cujas pesquisas são influenciadas por pesquisadores internacionais como Baltar (1996), Douady \& Perrin-Glorian (1989).

Essas pesquisas revelam a confusão dos alunos entre os conceitos de área e perímetro. Segundo BELLEIMAN e LIMA (2000, p.2), esses conceitos são "dos mais importantes no ensino-aprendizagem da matemática" e relevantes "para a formação do cidadão pleno", visto que, em suas atividades cotidianas, tem a necessidade de medir regiões planas como terrenos, pisos, paredes, faces de objetos. Além de sua relevância utilitarista, o conceito de área é rico por interligar os outros eixos da matemática (números, grandezas e álgebra) e por suas aplicações em outras áreas do conhecimento, como a geografia.

A má formação dos professores de Matemática quanto ao domínio e clareza dos conteúdos tem fortes implicações nos resultados da aprendizagem dos alunos, como pode-se verificar 
pelos baixos índices apresentados nos SARESPs de 2007 e 2008 em relação aos conhecimentos geométricos.

A deficiência na formação de professores pode ser um dos fatores que vem contribuindo na maneira superficial de abordar esses conceitos, uma vez que ela interfere na prática docente. Para Fiorentini (1995), a forma como conhecemos e concebemos os conteúdos de ensino tem fortes implicações no modo como selecionamos e os reelaboramos didaticamente em saber escolar, especialmente no modo como os exploramos em nossas aulas.

Para auxiliar os alunos a formularem os conceitos de perímetro e área, é necessário que o professor tenha domínio dos conceitos de superfície, área e medida da área, bem como o de medidas. A importância do domínio do conteúdo é ressaltada por Tardif (2002), pois considera que a ausência do conhecimento transforma o professor num transmissor mecânico dos conteúdos contidos nos livros. Crescenti (2008) enfatiza que a falta de domínio do conteúdo pode fazer com que o professor, "deixe de ensiná-lo ou o ensine de maneira muito superficial e até mesmo com erros conceituais." (p. 89).

O professor é o mediador na elaboração conceitual, visto que suas intervenções intencionalizadas buscam (ou deveriam buscar) fazer com que os alunos saiam da posição onde se encontram em relação ao conhecimento e os façam avançar. Atividades que proporcionam a análise de figuras de formas iguais que possuem áreas diferentes; figuras de áreas iguais que possuem formas diferentes, e diferenciar contorno de região interna auxiliam na formação desses conceitos.

"O papel do educador-matemático é ajudar os alunos a adquirir conhecimentos e habilidades que lhes possibilitem uma interpretação desse espaço-processo que não ocorre de forma natural, necessitando de intervenção pedagógica" (NACARATO, 2001, p.86). Sendo assim, é de fundamental importância que o professor considere o erro do aluno como um conhecimento inadequado, porém significativo para que invista em outros procedimentos de ensino que levem o aluno a compreender, de forma correta, cientificamente falando, o conceito abordado. Em outras palavras, que o professor se utilize de outros modos de mediação para que o aluno, de fato, aprenda. Tal procedimento demanda do professor que analise o erro do aluno, refletindo sobre suas possíveis causas, a fim de superá-las.

O erro, mais do que apontar as dificuldades dos alunos, auxilia o professor na elaboração de estratégias de ensino na busca de uma aprendizagem significativa. Sendo assim, o fazer 
docente do professor não pode consistir exclusivamente em transmitir um conteúdo pronto. Seu fazer deve vir acompanhado de um componente indispensável - a reflexão sobre o que faz junto a seus alunos.

\section{Procedimentos metodológicos do estudo}

O desenvolvimento da pesquisa compreendeu duas etapas. A primeira, contou com a participação de alunos e a segunda com a participação de professores.

Como ponto de partida, 85 alunos, da $7^{\text {a }}$ série, de uma escola pública do interior do estado de São Paulo, responderam, individualmente, duas questões retiradas do SARESP 2007 e 2008, referentes ao cálculo do perímetro e área de uma figura. Foi entregue juntamente com a folha de questões, uma folha em branco para que os alunos pudessem justificar a alternativa escolhida a fim de tentarmos compreender como eles os resolveram, suas dificuldades e possíveis causas de erros. Destes, dezessete alunos escolhidos aleatoriamente foram convidados a participarem da entrevista, porém apenas treze aceitaram o convite.

Optamos por realizar entrevistas semiestruturadas como instrumento de coleta de dados. Afinal, as entrevistas devem ser usadas "sempre que se tem necessidade de dados que não podem ser encontrados em registros ou fontes documentárias" e, cujo conhecimento, "se espera que alguém esteja em condições de prover" (NOGUEIRA, 1975, p. 113).

Foram entrevistados três professores que preenchiam o critério de ser professor do Ensino Fundamental. A entrevista contou com 10 questões abertas de forma que o professor pudesse expor suas opiniões e ideias. Também lhes foram entregues as folhas com as resoluções dos alunos relativas às duas questões do SARESP e solicitado que as analisassem. $\mathrm{O}$ encontro com os professores aconteceu na escola onde eles lecionam e as entrevistas ocorreram durante o horário da ATPC (Aula de Trabalho Pedagógico Coletivo) desses professores.

Os dados foram analisados com base na literatura discutida, tendo presente os aspectos matemáticos e educacionais como referência de análise.

\section{Discussão dos resultados}

Por meio dos dados coletados com as entrevistas foi possível verificar que os professores não tiveram boa formação do conhecimento geométrico, não aprenderam profundamente essa área 
de conhecimento da Matemática e, portanto, encontram dificuldades de ensiná-la aos alunos. Demonstraram insegurança ao responder sobre a importância da Geometria no Ensino Fundamental, enfatizaram a relevância de seu estudo, porém limitaram à sua aplicabilidade na vida cotidiana. Disseram preferir ensinar Álgebra a Geometria. Essa preferência está atrelada a uma formação marcada pelo pouco ensino geométrico, ou até mesmo, ausência dele e na ênfase de um ensino aritmético e algébrico, tanto na formação básica quanto na licenciatura.

Eu prefiro ensinar Álgebra, pois a gente foi levado a pensar mais algebricamente do que geometricamente. Nunca dava tempo de aprender Geometria. (P1)

Sei mais Álgebra. Com ela você consegue resolver várias coisas...Eu resolvo Geometria dentro da Álgebra. Eu me sinto mais confortável com a Álgebra. (P2)

Não tenho preferência só me sinto mais desafiada pela Álgebra. (P3)

Fica bastante claro nesses depoimentos o que Nacarato (2001) afirma sobre a formação deficitária do professor, que em sua maioria não teve contato com os conteúdos geométricos enquanto estudantes. Para a educadora "a ausência da geometria na escolarização formal vem formando gerações de profissionais, principalmente professores, que desconhecem os fundamentos desse campo da matemática” (p. 85).

Posto isso, os conteúdos ensinados ou não, dependem da importância que o professor lhes atribui, aliado ao gosto de ensinar mais um assunto que outro.

Os professores entrevistados não aprenderam profundamente essa área de conhecimento da Matemática e, portanto, encontram dificuldades de ensiná-la aos alunos. Demonstraram insegurança ao responder sobre a importância da Geometria no Ensino Fundamental, enfatizaram a relevância de seu estudo, porém limitaram à sua aplicabilidade na vida cotidiana.

P2 coloca que a Geometria é o estudo das formas. "São as figuras, os planos, os sólidos, as áreas e as medidas." Para P1 e P3, Geometria é aquilo que se pode visualizar. "Com a Geometria o aluno muda a forma de ver o mundo. É só olhar que se vê Geometria." (P1); “É a Matemática mais presente na vida do aluno." (P3)

Sobre a prática de analisar as produções dos alunos, atividade que traz a possibilidade de entender, mais de perto, como se dá a apropriação do saber pelos estudantes, os professores assim se expressaram: 
O correto é a gente fazer isso toda vez, procurar entender por que o aluno errou. Mas isso não é fácil, tenho muitas aulas e muitos alunos. É inviável corrigir o exercício de cada um. Faço a correção na lousa e cada aluno corrige o seu caderno. (P1)

Uma prática que tem dado certo é trabalhar em grupo. Então, passo nos grupos e vou olhando como eles estão resolvendo os exercícios. Depois corrijo os exercícios na lousa e vou explicando conforme eles vão pedindo. $(\mathrm{P} 2)$

Nas minhas $5^{a}$ s séries eu procuro, sempre que dá, corrigir o caderno de cada aluno pra ver o que eles não estão conseguindo entender, pra ver se eles fizeram a tarefa. (P3)

Os depoentes relataram também que, muitas vezes, utilizam a correção das atividades como um momento de avaliação. Cabe ressaltar que analisar o que o aluno produz não implica, necessariamente, em ter que atribuir um conceito ou nota. Ao analisar a resolução de um exercício ou problema, o erro cometido pelo aluno na resolução de um problema pode ser usado como subsídio para planejamento de estratégias de ensino, para tanto o professor deve conhecer e buscar entender os erros.

Os erros fazem parte do processo de ensino-aprendizagem. É preciso que os professores não os eliminem, mas os considerem fontes significativas de conhecimento e os transformem em situação de aprendizagem. Para tal é imprescindível que o professor reflita sobre a própria ação, analisando e discutindo os erros dos alunos, as estratégias e recursos já realizados, para que possa modificá-los a fim de superar as possíveis causas dos mesmos.

Ao analisarem as produções dos alunos, os professores apontam que o erro ocorreu em razão da falta de domínio dos alunos em relação aos conceitos perímetro e área.

Eles misturaram tudo! Calcularam o perímetro pensando estar calculando a área. (P2)

Ficou evidente que os conceitos perímetro e área não estão bem compreendidos por eles. Afinal, uma grande parcela confunde perímetro e área, quando somam os quatro lados de um quadrado (perímetro) para calcular a área.

$\mathrm{O}$ fato de os conceitos área e perímetro corresponderem a objetos geométricos distintos, tanto do ponto de vista topológico, onde área associa-se à superfície e perímetro ao contorno, quanto dimensional, apontados por Baltar (1996), não são da compreensão dos alunos. 
Percebe-se que não houve uma aprendizagem significativa dos conceitos científicos, eles foram repassados e não (re)construídos pelos alunos. O ensino aconteceu pela transmissão da informação e sua recepção pelos estudantes, de forma passiva. Isso pode ser decorrente de atividades pouco diversificadas, não desafiadoras e com aulas de Matemática tradicionais: definições, exemplos, atividades de aplicação direta do conteúdo, acarretando na memorização temporária de algoritmos e definições.

Os professores participantes da pesquisa sinalizaram que o conceito perímetro é mais facilmente compreendido pelos alunos do que o conceito de área. No entanto, relatam que há grande confusão, por parte dos alunos, na realização de atividades que requerem os dois conceitos. Mas, se o aluno apreendeu o conceito perímetro, como pontuado, porque ele não o diferencia do conceito área?

P2 relata que os alunos têm muita dificuldade de entender o conceito área, mas que isso é decorrente do desinteresse e da indisciplina. Atribui somente ao aluno a responsabilidade do não entendimento do conteúdo.

Quando perguntado aos alunos o que eles entendiam por perímetro e área, assim se expressaram:

Os dois são praticamente iguais, só que um você soma e o outro multiplica. (ALUNO A)

Perímetro são os lados, o que tem fora. Área é o que tá dentro. Sei lá,... acho que é isso. (ALUNOS)

Perímetro é mais ou menos a área de fora e área é a área de dentro. (ALUNO V)

P1 e P3, assim relatam suas práticas pedagógicas:

Para ensinar perímetro eu sempre inicio com um exemplo: Seu pai comprou um terreno e precisa cercar ele. Quantos metros de tela ele vai usar para cercar o terreno inteiro, sabendo que o terreno tem $6 m$ por 25m? Depois de colocar esse exemplo na lousa, eu faço um desenho para que eles visualizem o terreno. Discuto com os alunos que para cercar o terreno, eles tem que somar todos os lados dele, assim chega-se que perímetro é a soma de todos os lados da figura. Pratico aquele tipo de exercício. É preciso ensinar Matemática exaustivamente. Precisa dar vários exercícios, de A a Z. (P1)

Para ensinar perímetro pro meus alunos eu sempre mostro a utilidade, dou 
exemplos da colocação de gesso, de rodapé, de cercar uma horta, etc. Dei aos meus alunos da $5^{a}$ série um pedaço de barbante e pedi que eles me dissessem quantos centímetros de barbante eu uso para dar a volta na carteira. Eles então contornaram a carteira e depois mediram o pedaço numa fita métrica. Só que muitos não sabem medir, não sabe se começa do zero ou do um. Mas, é assim, que tento construir a ideia de perímetro. Depois com os dados, discuto com eles que sabendo as medidas das figuras eu posso chegar ao perímetro sem precisar utilizar o barbante e aí chego na fórmula. (P3)

Analisando as falas dos alunos e a maneira pela qual os professores ensinam, é possível perceber que o processo de ensino-aprendizagem desses conceitos é pautado no modelo psicopedagógico da mera transmissão-recepção.

É relevante pontuar a prática pedagógica de P1. Ela nos remete à maneira tradicional de ensino, onde o aluno deve interiorizar o que lhe é ensinado e repetir o que aprendeu. O papel desempenhado pelo professor é o de transmissor de conhecimento, seu método de ensino baseia-se em aulas expositivas, com exercícios de fixação. Essa maneira de conceber o ensino é chamada por Freire (2005) de concepção bancária da educação.

Nessa concepção, a educação é o ato de transferir/transmitir/depositar os conhecimentos, e os alunos se transformam em "vasilhas" a serem "enchidas" que, pacientemente, memorizam e repetem.

Percebemos, pelas falas dos professores, duas maneiras de transmitir o conceito perímetro. P1 apresenta perímetro como sendo a soma dos lados de uma figura, bastando ao aluno memorizar a regra e aplicá-la nos exercícios; e não, de entendê-la. O professor acaba priorizando a memorização em vez da (re)construção do conceito.

Quando o professor, para "facilitar" o cálculo da medida do perímetro, o define como "a soma de todos os lados", pode acarretar num obstáculo verbal, de acordo com Bachelard (1996). Segundo o epistemólogo "uma linguagem demasiado fácil de manejar pode bloquear muito tempo uma reformulação necessária”. O obstáculo verbal é “a falsa explicação obtida com a ajuda de uma palavra explicativa" (p.27). Há aqui, além de um obstáculo epistemológico, um erro conceitual, pois perímetro é a soma das medidas dos lados.

Já P3 parte da ideia de contorno para a construção do conceito perímetro. Essa prática é importante, uma vez que nem todas as figuras são formadas por segmentos de retas, como é o caso do círculo e de figuras irregulares. 
O termo "passar" conteúdo utilizado várias vezes por P1 enfatiza que sua prática pedagógica se pauta no mero repasse de conceitos, o processo de ensino - aprendizagem é embasado no modelo transmissão-reprodução. Essa prática de ensino voltada para a transmissão de informações científicas de forma acabada e inquestionável é destituída de significado.

Sobre isso Vygostky assevera que

\begin{abstract}
(...) o ensino direto de conceitos é impossível e infrutífero. Um professor que tenta fazer isso geralmente não obtém qualquer resultado, exceto o verbalismo vazio, uma repetição de palavras pela criança, semelhante à de um papagaio, que simula um conhecimento dos conceitos correspondentes, mas que na realidade oculta um vácuo. (VYGOSTKY, 2008b, p.104).
\end{abstract}

$\mathrm{Na}$ ânsia por buscar trabalhar a Matemática de maneira contextualizada, os professores utilizam exemplos inadequados para abordar os conceitos. Qual é o significado, para estudantes de uma faixa etária de 12, 13 anos, cercar um terreno, colocar gesso, rodapé, pisos? Que vivência eles tem disso? Esse tipo de exemplo, entretanto, poderia ser bastante significativo para um grupo de alunos na Educação de Jovens e Adultos (EJA).

Pelo relato, a maioria das atividades propostas pelos professores trata do cálculo de perímetro e área de figuras usuais, onde a aplicação imediata da fórmula resolve a questão. Pouco se trabalha com atividades que possibilitam aos alunos perceberem que uma mesma figura pode ser ou não (de)composta em outras figuras geométricas, o que proporciona uma construção significativa do conhecimento matemático, visto que os alunos precisam identificar, interpretar, elaborar e criar estratégias de resolução.

Já em relação ao ensino de área, percebe-se, pelas falas dos depoentes, que o conceito é apresentado pela fórmula pronta para o cálculo, o que não favorece o processo de construção da mesma.

O conceito área é abordado, pelos professores, a partir de exemplos como: Calcule a área de um terreno de 6x25m. João quer trocar o piso de sua sala de aula. Quantos metros quadrados de piso ele utilizará para efetuar a troca, sabendo que ela mede $5 \mathrm{~m}$ por $4 \mathrm{~m}$ ? Com esse exemplo, P3 procura mostrar aos alunos que ao preencher totalmente o espaço da sala eles estão determinando a área da mesma.

Os docentes da pesquisa utilizam problemas cuja solução deve ser buscada no emprego das definições e algoritmos discutidos em aula, ou seja, são problemas de aplicação. Um exemplo é a fala de P3: 
Em uma de minhas aulas, entre os exercícios de cálculo de área, passei as dimensões da sala de aula e pedi aos alunos que calculassem sua área. Como a sala é retangular bastava para responder multiplicar o valor dos lados. Queria ver se tinham entendido como calcular a área de um retângulo. Passado algum tempo percebi que muitos alunos começaram a contar a quantidade de piso que a sala tinha para responder a questão.

Pesquisadora: E você questionou algum aluno porque ele estava contando a quantidade de pisos?

Na hora não. Foi difícil me controlar para não falar pra eles que não era daquele jeito, mas eu deixei para ver. Na hora da correção das atividades eu mostrei pra eles que a quantidade de piso não era a área da sala. Para calcular a área era preciso usar a fórmula do retângulo, $A=b \times h$.

Pesquisadora: Você já parou para tentar entender o que levou os alunos a acharem que, contando a quantidade de pisos, eles descobririam a área da sala?

Eu corrigi as atividades na lousa e expliquei como resolver cada exercício, utilizando as fórmulas. Mas pensando agora, eu acho que como eu tinha trabalhado com a malha quadriculada com eles e para calcular a área era só contar a quantidade de quadradinhos e pelo piso ser quadrado, eles acharam que contando a quantidade de piso chegava também na área. Só pode ter sido isso.

É notório que os alunos de P3, durante a atividade, não consideraram que a unidade de medida requerida era $\mathrm{o} \mathrm{m}^{2}$ e não levaram em conta que a lajota não era um quadrado de $1 \mathrm{~m} \mathrm{x}$ $1 \mathrm{~m}$, sendo assim a quantidade de lajotas, não representava a medida da área da sala, em $\mathrm{m}^{2}$.

Com esse exemplo, percebemos que o conceito de unidade (importante para a construção do conceito de medida) não foi apreendido pelos alunos. Poderia ter sido sugerido aos alunos que utilizassem uma lajota como unidade de medida da superfície e, também, a construção de um quadrado com $1 \mathrm{~m}$ de lado, para que eles, utilizando desse instrumento, verificassem quantos $1 \mathrm{~m}^{2}$ cabem na sala de aula, auxiliando-os na compreensão de que apesar de unidades de medidas diferentes, a área daquela superfície não se altera.

Foi durante o relato de sua aula que P3 parou para analisar e tentar entender o motivo pelo qual os alunos começaram a contar os pisos para achar a área da sala. A pergunta levantada pela pesquisadora proporcionou a P3 retomar sua prática e analisar, a posteriori, sua ação, no sentido de compreender e reconstruí-la. Refletir sobre a ação é importante, pois um professor com pensamento prático consegue compreender os processos de ensino-aprendizagem e 
aprende a construir e a comparar novas estratégias de ação, novas teorias, novos modos de enfrentar e definir os problemas. Além de atentar que seus alunos amadurecem de maneiras e tempos diferentes (PÉREZ GÓMEZ, 1992).

As práticas de P1 e P2 podem ser associadas com a prática denominada por Valente (2008, p.22) de "escrever exercícios a serem resolvidos pelos alunos". Segundo o autor, ela é herança do início do século XX, dos livros franceses cheios de exercícios. O professor nunca mais abandonou essa prática, na qual resolver o exercício de maneira correta significa aprender Matemática. Tem-se, assim, um profissional que concebe o ensino como uma mera transmissão de conceitos já elaborados e construídos.

P3 se vale também dessa prática, mas apresenta, muitas vezes, um diferencial ao ensinar os conceitos a seus alunos. Como exemplo, tomemos o conceito de perímetro. Os alunos recebem um pedaço de barbante e lhes é pedido que contornem alguns objetos, tais como: a carteira, uma tampa de panela, a face de uma caixa. Assim parte-se da ideia de contorno para elaboração do conceito de perímetro.

Grando, Nacarato e Gonçalvez (2008) afirmam que o ensino da Geometria pautado nas tarefas exploratório-investigativas vem se mostrando favoráveis para "minimizar algumas das lacunas existentes em decorrência do pouco ensino de conteúdos geométricos na educação básica" (p.44).

Não podemos deixar de pontuar a maneira com que P3 aborda o conceito de medida com seus alunos:

"Antes de ensinar perímetro, eu peço a meus alunos que meçam as carteiras deles com os palmos, depois com os braços e só depois com a régua."

Medir é um processo complexo, pois envolve a escolha de uma unidade de medida e atribuise a uma grandeza, um número, que é a medida da grandeza na unidade escolhida. Oportunizar aos alunos atividades de medição utilizando unidades não-convencionais pode auxiliá-los a entender que é necessário adequar unidade à grandeza a ser medida.

Para tanto, é preciso que o professor tenha conhecimento epistemológico dos conteúdos bem como condições de fazer as necessárias reelaborações conceituais daqueles que ensinam, para, assim, viabilizar melhores práticas em Matemática. O grande dilema dos professores da pesquisa é a deficiência na sua formação. 


\section{Considerações finais}

Fazendo uma análise sobre o processo ensino-aprendizagem dos conceitos área e perímetro e como vem sendo praticado o ensino de Grandezas Geométricas nas escolas de Ensino Fundamental, nas quais se inserem os professores e alunos participantes da pesquisa, fica evidente a fragilidade do ensino do conhecimento geométrico na formação inicial do docente.

Como ensinar o que não se aprendeu? Por conta de uma formação deficitária, pautam-se em tradicionais práticas de ensino, definição do conceito, repassam-se regras prontas para aplicação direta do conteúdo, prioriza-se a memorização da fórmula do cálculo da área e do perímetro, em vez de centrar-se na (re)construção desses conceitos. A escolha didática desses professores parece não favorecer a apropriação dos conceitos.

É perceptível que o ensino pautado na transmissão-recepção passiva de informações não é significativo aos alunos e de nada contribui para a formação dos conceitos. Concordamos com Paulo Freire que "Ensinar não é transferir conhecimento, mas criar as possibilidades para a sua produção ou a sua construção" (FREIRE, 1996, p.25).

O professor de Matemática deve compreender que é um mediador do processo de construção do conhecimento matemático e, para isso, sua prática, deve oportunizar aos estudantes exercitarem a capacidade de buscar soluções para os problemas, haja visto que o ritual de apresentação do conceito, das propriedades, da fórmula, do algoritmo e da série de exercícios de aplicação com modelos repetitivos, não está sendo eficaz, como constatado na pesquisa.

Sendo assim, para auxiliar o aluno a formular os conceitos de perímetro e área, o professor precisa propiciar atividades de comparação de grandezas sem a necessidade de medição como, por exemplo, comparar dois caminhos, duas áreas utilizando a composição e decomposição de figuras. Atividades intencionalmente orientadas para que os estudantes compreendam, primeiramente, os conceitos de unidade, importante para a construção do conceito de medida, como colocado por Caraça (1951). É necessário, também, solicitar atividades nas quais a área varie em sentido oposto ao de seu perímetro, favorecendo a compreensão e diferenciação desses conceitos. Em suma, atividades que articulem e diferenciem a figura, a grandeza a ela associada e a medida dessa grandeza.

Olhar o erro do aluno, a sua maneira de solucionar um problema, é um indicativo para que repensemos nossas práticas de ensino. Ficou explícito que é através da reflexão na ação e na reflexão sobre a reflexão na ação que o professor conversa consigo mesmo e compreende a 
forma como ensina.

A prática de analisar as produções/erros dos alunos propiciou a P3 analisar, repensar sua prática pedagógica. Assim, o erro tornou-se elemento de reflexão.

Considero que se faz necessário, para que o ensino de Grandezas Geométricas, em especial o de perímetro e área, possa contribuir para que os alunos os apreendam de forma significativa, que a formação básica capacite os futuros professores na aquisição do conhecimento tanto Geométrico quanto o das Grandezas e Medidas, para que possam ser por eles ensinados com segurança.

Segundo Gatti (2009), os cursos de Licenciatura em Matemática dispõem 1,6\% da sua carga horária para a disciplina Didática Geral. Ela verificou também, que em termos de número de horas, há uma maior proporção de horas-aula dedicadas às disciplinas relativas a conhecimento específicos da área que para às disciplinas específicas para a docência.

Em relação à formação continuada, que sejam promovidos pela Diretoria de Ensino cursos para reflexão sobre a prática, e que sejam ministrados por profissionais especializados na área de formação e em horários acessíveis aos professores - o que pode favorecer a ampliação do conhecimento geométrico e das medidas, tanto no conteúdo específico quanto no pedagógico.

No que tange à escola, é recomendável melhor aproveitamento da ATPC, utilizando-a como espaço de formação continuada.

\section{Referências}

ANDRADE, J. B. Composição e decomposição de figuras geométricas planas por alunos do ensino médio. 2007. 120p. Dissertação (Mestrado Profissional em Ensino da Matemática). Pontifícia Universidade Católica de São Paulo, São Paulo, SP, 2007.

BACHELARD, G. A formação do espírito científico - contribuição para uma psicanálise do conhecimento. Trad.: Estela dos Santos Abreu. Contraponto, 1996.

BALDINI, L. A. F. Construção do conceito de área e perímetro: uma seqüência didática com auxílio de software de geometria dinâmica. 2004. 179p. Dissertação (Mestrado em Ensino de Ciências e Educação Matemática) - Universidade Estadual de Londrina, PR, 2004.

BELLEMAIN, P. M. B. e LIMA, P.F. Análises prévias à concepção de uma engenharia de formação continuada para professores de matemática do ensino fundamental. Anais da $23^{\mathrm{a}}$ reunião anual da ANPED - Caxambu. 2000.

CARAÇA, B. J. Conceitos fundamentais da Matemática. Lisboa, 1951. 
CHIUMMO, A. O conceito de áreas de figuras planas: capacitação para professores do ensino fundamental. 1998. 142p. Dissertação (Mestrado em Ensino da Matemática). Pontifícia Universidade Católica de São Paulo, São Paulo, SP, 1998.

CRESCENTI, E. P. A formação inicial do professor de matemática: aprendizagem da Geometria e atuação docente. Práxis Educativa, Ponta Grossa, PR, v.3, n.1, p.81-94, 2008.

Os professores de matemática e a geometria: opiniões sobre a área e seu ensino. 2005. Tese (Doutorado em Educação). UFSCAR, São Carlos, SP.

FACCO, S. R. Conceito de área: uma proposta de ensino aprendizagem. 2003. 149p. Dissertação (Mestrado em Educação Matemática). Pontifícia Universidade Católica de São Paulo, São Paulo, SP, 2003.

FIORENTINI, D. Alguns modos de ver e conceber o ensino da matemática no Brasil. Zetetiké, Campinas, SP, Ano 3 - n. 4, p. 1-37, 1995.

FREIRE, P. Pedagogia da autonomia: saberes necessários à prática educativa. São Paulo: Paz e Terra, 1996.

GATTI, B. A.; NUNES, M. M. R (orgs). Formação de professores para o ensino fundamental: estudo de currículos das licenciaturas em pedagogia, língua portuguesa, matemática e ciências biológicas. São Paulo: FCC/DPE, 2009.

GAZIRE, E. S. O não resgate das geometrias. 2000. 218p. Tese (Doutorado em Educação) UNICAMP, Campinas, SP, 2000.

GRANDO, R. C.; NACARATO, A. M.; GONÇALVES, L. M. G. Compartilhando saberes em Geometria: Investigando e aprendendo com nossos alunos. Cadernos Cedes, Campinas, vol.28, n.74, p.39-56, jan./abr. 2008.

LOREnZATO, S. Por que não ensinar Geometria? A Educação Matemática em Revista. SBEM, ano 3, p. 3 - 13, jan/jun. 1995.

NACARATO, A. M. A geometria no ensino fundamental: fundamentos e perspectivas de incorporação no currículo das séries iniciais. In SISTO, Fermino F.; DOBRÁNSZKY, E. A.; MONTEIRO, A. (orgs). Cotidiano escolar: questões de leitura, matemática e aprendizagem. Petrópolis: Vozes; Bragança Paulista: USF, 2001, p. 84-99.

NACARATO, A. M.; PASSOS, C. L.B. A geometria nas séries iniciais: uma análise sob a perspectiva da prática pedagógica e da formação de professores. São Carlos: EdUFSCar, 2003.

PAVANELLO, R. M. O abandono do ensino da geometria no Brasil: causas e consequências. Zetetiké, Campinas, SP, ano1, n.1, p. 7- 17, mar.1993.

O abandono do ensino de geometria: uma visão histórica. 1989. Dissertação (Mestrado em Educação). UNICAMP, Campinas, SP, 1989. 
PÉREZ GÓMEZ, A. O pensamento prático do professor: a formação do professor como profissional reflexivo. In: NÓVOA, António (org). Os professores e sua formação. Lisboa: Dom Quixote, 1992, p. 92-114.

TARDIF, M. Saberes docentes e formação profissional. Tradução Francisco Pereira. Petrópolis: Vozes, 2002.

VALENTE, W. R. Quem somos nós, professores de matemática? Cadernos Cedes. Campinas, vol. 28, n. 74, p.11-23, jan./abr.2008. 